\title{
FORMULASI SEDIAAN EMULGEL DAUN PIDADA MERAH (SONNERATIA CASEOLARIS L.) SEBAGAI ANTI JERAWAT
}

\author{
Nurul Hasanah*, Hajrah, Lisna Meylina, Laode Rijai \\ Laboratorium Penelitian dan Pengembangan FARMAKA TROPIS \\ Fakultas Farmasi Universitas Mulawarman, Samarinda, Kalimantan Timur \\ *email: nurulnameii@gmail.com
}

\begin{abstract}
ABSTRAK
Daun Pidada Merah (Sonneratia caseolaris L) memiliki kandungan senyawa fenolik yang memiliki aktivitas antibakteri Propionibacterium acne sehingga berpotensi untuk diformulasikan menjadi sediaan anti jerawat yang diformulasikan dalam bentuk sediaan emulgel. Penelitian ini bertujuan untuk memperoleh formula terbaik dari sediaan emulgel ekstrak daun Pidada Merah. Emulgel diformulasikan dengan menggunakan minyak zaitun dan minyak VCO sebagai fase minyak, Tween 80 dan Cremophor RH 40 sebagai surfaktan serta karbopol 940 dan Viscolam MAC 10 sebagai gelling agent. Evaluasi fisik meliputi pengamatan organoleptis, uji homogenitas, penetapan $\mathrm{pH}$, uji daya sebar, uji viskositas dan uji sentrifugasi. Uji aktivitas anti jerawat sediaan dilakukan dengan metode difusi agar sumuran. Hasil penelitian menunjukkan bahwa formula emulgel yang paling baik adalah F5, F6, F7 dan F8. Uji aktivitas anti jerawat menunjukkan bahwa sediaan emulgel F5, F6, F7 dan F8 mempunyai daya hambat terhadap Propionibacterium acnes.
\end{abstract}

Kata kunci: Pidada merah, emulgel, anti jerawat

\begin{abstract}
Sonneratia caseolaris L contains phenolic compounds which possess antibacterial activity Propionibacterium acnes, so the potential to be formulated into anti-acne preparations formulated in dosage forms emulgel. This study aimed to obtain the best formula of the preparation emulgel Sonneratia caseolaris L extract. Emulgel formulated using olive oil and VCO as an oil phase, Tween 80 and Cremophor RH 40 as surfactant, Carbopol and Viscolam MAC 10 as a gelling agent. Physical evaluation includes observation organoleptic, homogeneousness, determination of $\mathrm{pH}$, dispersive power test, viscosity and centrifugation test. Anti-acne activity of this research used diffusion well method. The results showed that the formula is best emulgel F5, F6, F7 and F8. Anti-acne activity test showed that preparation emulgel F5, F6, F7 and F8 have inhibitory effect on Propionibacterium acnes.
\end{abstract}

Keywords: Sonneratia caseolaris L, emulgel, anti acne

\section{PENDAHULUAN}

Salah satu penyakit kulit yang dapat mengurangi kepercayaan diri seseorang ialah jerawat. Jerawat merupakan suatu penyakit kulit yang berupa peradangan kronik folikel polisebasea, yang disebabkan oleh adanya perubahan pola keratinisasi folikel, produksi sebum yang berlebih, dan peningkatan flora folikel seperti Propionibacterium acne (Depkes RI, 2000).

Salah satu tumbuhan dari alam yang dapat dimanfaatkan sebagai antibakteri adalah daun pidada merah (Sonneratio caseolaris) (Mahadlek, 2012). Hasil penelitian sebelumnya 
yang dilakukan oleh Mahadlek (2012) dilaporkan bahwa daun pidada merah (Sonneratio caseolaris) mempunyai aktivitas antibakteri terhadap bakteri Propionibacterium acne.

Emulgel merupakan gel dengan cairan berbentuk emulsi, biasanya untuk menghantarkan minyak yang merupakan zat aktif dalam sediaan tersebut, dengan mengurangi kesan berminyak saat diaplikasikan pada kulit untuk tujuan penggunaan lokal (Voigt, 1994).

Tujuan dalam penelitian adalah mengetahui aktivitas antibakteri ekstrak metanol daun Pidada Merah (Sonneratia caseolaris) terhadap Propionibacterium acnes setelah diformulasikan dalam bentuk sediaan emulgel.

\title{
METODE PENELITIAN
}

\section{Bahan Penelitian}

Aquades, Carbopol 940, Cremophor RH 40, Gliserin, Metil Paraben, Minyak VCO, Propilenglikol, Propil Paraben, TEA, Tween 80, Propionibacterium acne, medium TSA dan Viscolam MAC 10.

\begin{abstract}
Alat Penelitian
Alat-alat yang digunkan dalam penelitian ini adalah wadah maserasi, Rotary evaporator, water bath, desikator, timbangan analitik, spatel, sendok tanduk, corong, pipet tetes, pipet ukur, mikropipet, bunsen, kaca arloji, labu ukur, botol vial, paper disc, erlenmeyer, tabung reaksi, cawan petri, ose bulat, autoclave, laminar air flow, freezer, inkubator, oven, mikrsometer sekrup, mortir, stamper, gelas kimia, batang pengaduk, magnetic stirer, objek gelas dan $\mathrm{pH}$ meter.
\end{abstract}

\section{Prosedur Penelitian}

\section{Formulasi Emulgel}

Fase minyak (minyak $V C O$ ) ditambahkan dengan surfaktan (Cremophor $\mathrm{RH} 40$ dan Tween 80) kemudian diaduk hingga homogen. Setelah itu ditambahkan aquades perlahan dan diaduk hingga terbentuk basis emulsi.

Carbopol dikembangkan dengan air sedikit demi sedikit sambil diaduk perlahan-lahan sampai terbentuk massa gel. Kemudian ditambahkan TEA dan gliserin digerus hingga homogen. Dilarutkan metil paraben dan propil paraben ke dalam propilenglikol. Kemudian campuran ditambahkan pada basis gel dan digerus hingga homogen.

Viscolam MAC 10 ditambahkan dengan aquades lalu diaduk hingga homogen. Ditambahkan TEA tetes demi tetes hingga terbentuk massa gel. Ditambahkan gliserin dicampur hingga homogen. Dilarutkan metil paraben dan propil paraben ke dalam propilenglikol. Kemudian campuran ditambahkan pada basis gel dan digerus hingga sediaan homogen. Dicampurkan basis emulsi dan basis gel lalu digerus hingga terbentuk emulgel. Dilarutkan ekstrak daun pidada merah dalam propilenglikol kemudian ditambahkan ke dalam basis emulgel dan digerus hingga homogen. Dapat dilihat pada tabel 1.

\section{Evaluasi Sediaan}

Basis yang telah terbentuk diamati secara organoleptik dengan melihat warna dari basis. Diukur $\mathrm{pH}$ basis dengan menggunakan $\mathrm{pH}$ meter lalu diuji viskositas, homogenitas, viskositas dan daya sebarnya. Setelah itu basis dicampurkan dengan ekstrak metanol daun pidada merah yang telah diuji sebelumnya, kemudian sediaan dievaluasi seperti basis serta dilakukan uji sentrifugasi dengan cara mensentrifugasi sediaan krim pada kecepatan 3800 rpm selama 5 jam, kemudian diamati perubahan fisiknya apakah terjadi pemisahan. 


\section{Pengujian Aktivitas Antijerawat Emulgel Pidada Merah}

a. Penyiapan Alat dan Pembuatan Medium Nutrient Agar

Cawan petri dan tabung reaksi dicuci dan dikeringkan, lalu dibungkus menggukan kertas dan untuk tabung reaksi ditutup mulutnya menggunkan kapas terlebih dahulu. Sterilisasi dilakukan dengan menggunakan Autoclave dan dilakukan bersamaan dengan sterilisasi medium. Sebelum disterilisasi 5 gram medium nutrient agar dilarutkan dengan aquadest $25 \mathrm{~mL}$ dalam erlenmeyer lalu diaduk di atas hotplate hingga tampak jernih. Setelah itu disterilisasi dengan suhu $121^{\circ} \mathrm{C}$ selama 15 menit. Medium yang sudah steril didinginkan dan disimpan didalam Freezer.

\section{b. Pembuatan Suspensi Mikroba}

Biakan Propionibacterium acne diinokulasi ke dalam tabung reaksi baru yang berisi medium TSA dan diinkubasi dalam suhu $37^{\circ} \mathrm{C}$ selama $1 \times 24$ jam untuk memperoleh biakan baru. Biakan yang didapat kemudian disuspensikan dengan $\mathrm{NaCl} 0,9 \%$ sampai dengan perbandingan 1:60.

\section{c. Pengujian aktivitas}

Suspensi bakteri disebarkan secara merata di atas permukaan media dengan menggunakan lidi kapas steril. Dibiarkan \pm 3 menit, kemudian dibuat sumuran $9 \mathrm{~mm}$ dan dimasukkan emulgel ke dalam sumuran. Diinkubasi selama 24 jam pada suhu $\pm 37^{\circ} \mathrm{C}$ dalam inkubator. Diamati dan diukur diameter daya hambat yang terbentuk dengan mikrometer sekrup yang ditandai dengan terbentuknya daerah bening di sekitar sumuran.

\section{HASIL DAN PEMBAHASAN}

Hasil penelitian ini membahas tentang formula sediaan emulgel dengan bahan aktif antijerawat dari ekstrak metanol daun pidada merah. Formula emulgel terbuat dari ekstrak metanol daun pidada merah dan basis dengan variasi formula yaitu dua jenis fase minyak, dua jenis gelling agent dan dua jenis surfaktan. Basis emulgel terdiri dari fase minyak (minyak VCO dan Zaitun), surfaktan (Tween 80 dan Cremophor RH 40), gelling agent (Viscolam MAC 10 dan Carbopol 940), humektan (Propilen glikol), gliserin, metil paraben, propil paraben dan air suling. Konsentrasi ekstrak yang digunakan pada formula F1 dan F8 adalah $2,5 \%$.

Tabel. $1 \quad$ Formula Sediaan Emulgel Daun Pidada Merah

\begin{tabular}{lcccccccc}
\hline \multirow{2}{*}{ Komposisi (g/mL) } & \multicolumn{7}{c}{ Formula } \\
\cline { 2 - 9 } & F1 & F2 & F3 & F4 & F5 & F6 & F7 & F8 \\
\hline Ekstrak & 2,5 & 2,5 & 2,5 & 2,5 & 2,5 & 2,5 & 2,5 & 2,5 \\
Minyak VCO & 2 & - & 2 & - & 2 & - & 2 & - \\
Minyak Zaitun & - & 2 & - & 2 & - & 2 & - & 2 \\
Carbopol 940 & 1 & 1 & 1 & 1 & - & - & - & - \\
Viscolam MAC 10 & - & - & - & - & 20 & 20 & 20 & 20 \\
Tween 80 & 14 & 14 & - & - & 14 & 14 & - & - \\
Cremophor RH 40 & - & - & 14 & 14 & - & - & 14 & 14 \\
TEA & 1 & 1 & 1 & 1 & 1 & 1 & 1 & 1 \\
Gliserin & 5 & 5 & 5 & 5 & 5 & 5 & 5 & 5 \\
Propilenglikol & 15 & 15 & 15 & 15 & 15 & 15 & 15 & 15 \\
Metil Paraben & 0,2 & 0,2 & 0,2 & 0,2 & 0,2 & 0,2 & 0,2 & 0,2 \\
Propil Paraben & 0,05 & 0,05 & 0,05 & 0,05 & 0,05 & 0,05 & 0,05 & 0,05 \\
Aquadest ad & 100 & 100 & 100 & 100 & 100 & 100 & 100 & 100 \\
\hline
\end{tabular}


Tabel. 2 Hasil Pengamatan Organoleptis, pH, Viskositas dan Daya Sebar Sediaan

\begin{tabular}{|c|c|c|c|c|c|c|c|c|}
\hline Evaluasi & F1 & F2 & F3 & F4 & F5 & F6 & F7 & F8 \\
\hline $\mathrm{Bau}$ & Khas & Khas & Khas & Khas & Khas & Khas & Khas & Khas \\
\hline Homogenitas & $\mathrm{V}$ & $\mathrm{V}$ & $\mathrm{V}$ & $\mathrm{V}$ & $\mathrm{V}$ & $\mathrm{V}$ & $\mathrm{V}$ & $\mathrm{V}$ \\
\hline Warna & $\mathrm{HK}$ & $\mathrm{HK}$ & $\mathrm{HK}$ & $\mathrm{HK}$ & HK & $\mathrm{HK}$ & $\mathrm{HK}$ & $\mathrm{HK}$ \\
\hline Fisik basis & K & K & K & K & K & K & K & K \\
\hline Fisik basis+ekstrak & AKT & $\mathrm{C}$ & AKT & $\mathrm{C}$ & K & K & K & K \\
\hline $\mathrm{pH}$ basis & 5,85 & 5,98 & 5,70 & 5,80 & 6,05 & 6,20 & 6,15 & 6,12 \\
\hline $\mathrm{pH}$ basis+ekstrak & 5,39 & 5,07 & 5,48 & 5,24 & 5,93 & 5,92 & 5,93 & 5,89 \\
\hline Viskositas basis (pa.s) & 5,36 & 5,17 & 5,61 & 5,83 & 6,03 & 9,53 & 6,17 & 10,14 \\
\hline Viskositas basis+ekstrak & 1,54 & 0,24 & 3,66 & 2,39 & 3,64 & 4,06 & 3,25 & 3,25 \\
\hline Daya sebar basis+ekstrak & 6,5 & 8,5 & 6,6 & 6,7 & 5,6 & 5,1 & 5,2 & 5,0 \\
\hline $\begin{aligned} \text { terangan } & \mathrm{v} \\
& \mathrm{HK}=\end{aligned}$ & $\begin{array}{l}\text { loge } \\
\text { ecok }\end{array}$ & & $\begin{array}{l}\mathrm{K} \\
\mathrm{AK}\end{array}$ & & $\begin{array}{l}\mathrm{tal} \\
\mathrm{k} \mathrm{K}\end{array}$ & $\mathrm{C}$ & Cair & \\
\hline
\end{tabular}

Evaluasi sediaan emulgel ditinjau berdasarkan parameter-parameter yaitu pengamatan organoleptis, homogenitas, $\mathrm{pH}$, viskositas dan daya sebar. Pengamatan organoleptis sediaan emulgel formula F1, F2, F3, F4, F5, F6, F7 dan F8 adalah hijau kecoklatan. Kedelapan formula memiliki bau yang khas. Pengujian homogenitas dari kedelapan formula menunjukkan sediaan yang homogen. Uji $\mathrm{pH}$ sediaan menunjukkan formula emulgel formula F1, F2, F3, F4, F5. F6, F7 dan F8 memenuhi syarat dan masuk dalam rentang $\mathrm{pH}$ kulit yaitu 4,5-6,5. Uji daya sebar emulgel memenuhi syarat daya sebar yang baik yaitu $5-7 \mathrm{~cm}$. Uji viskositas menunjukkan perbedaan hasil yang disebabkan adanya variasi penggunaan gelling agent pada sediaan emulgel yang diformulasikan. Emulgel dengan basis gel carbopol memiliki viskositas yang lebih kecil dibandingkan dengan emulgel dengan basis gel Viscolam serta tidak memenuhi syarat viskositas sediaan emulgel yang baik yakni 4-6 Pa. Sehingga, dari kedelapan formula diambil empat formula terbaik yakni formula dengan basis gel Viscolam. Berdasarkan uji sentrifugasi diperoleh hasil semua formula tidak mengalami perpisahan fase.

Berdasarkan hasil dari evaluasi sediaan yang telah dilakukan maka, diperoleh empat formula terbaik yakni F5, F6, F7 dan F8. Keempat formula emulgel kemudian diuji aktivitas antijerawat dengan menggunakan metode difusi agar sumuran. Diperoleh hasil yaitu keempat formula memiliki daya hambat terhadap bakteri Propionibacterium acne.

Tabel. 3 Hasil Pengujian Aktivitas Antijerawat Emulgel Pidada Merah

\begin{tabular}{ccc}
\hline Formula & Hasil Pengujian \\
\hline F5 & Zona Hambat \\
F6 & Zona Hambat \\
F7 & Zona Hambat \\
F8 & Zona Hambat \\
\hline Keterangan & $:$ F5 = Viscolam MAC 10, M. VCO dan Tween 80 \\
& F6 = Viscolam MAC 10, M. Zaitun dan Tween 80 \\
& F7 = Viscolam MAC 10, M. VCO dan Cremophor RH 40 \\
& F8 = Viscolam MAC 10, M. Zaitun dan Cremophor RH 40
\end{tabular}




\section{KESIMPULAN}

Berdasarkan evaluasi sediaan emulgel secara kimia dan fisik terpilih 4 formula terbaik yakni F5, F6, F7 dan F8. Formula F5, F6, F7 dan F8 sediaan emulgel berbahan aktif ekstrak metanol daun Pidada Merah memiliki daya hambat terhadap Propionibacterium acne.

\section{DAFTAR PUSTAKA}

Depkes RI. 2000. Kapita Selekta Kedokteran. Edisi III, Jilid 2, 126. Departeman Kesehatan Republik Indonesia. Jakarta.

Mahadlek, J., T. Phachamud and C.Wessapun. 2012. Antimicrobial studies of Sonneratia caseolaris using different agar diffusion method. Res. J. Pharm. Biol. Che. Sci., 3(1):404-410.

Voigt, R. 1994. Buku Pelajaran Teknologi Farmasi. Penerjemah Dr. Soendani Noerono. Edisi Kelima. Gadjah Mada University Press. Yogyakarta. 